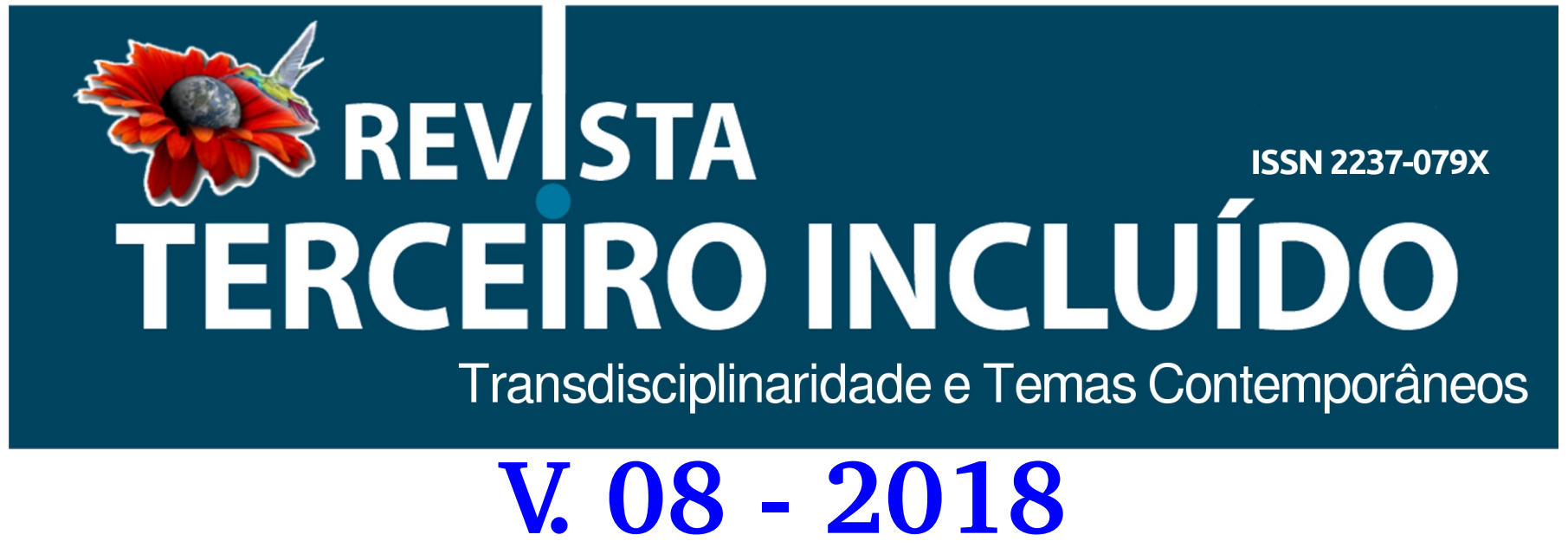

MELO FILHO, José Sebastião de; VÉRAS, Mário Leno Martins; de MELO, Urandy Alves ALVES, Lunara de Sousa ; COSTA, Fabiana Xavier.

Identificação De Visitantes Florais Na Cultura Do Feijão Caupi Em Pombal-PB pp. 85-93

DOI: $10.5216 /$ teri.v8i1.40154 


\title{
IDENTIFICAÇÃO DE VISITANTES FLORAIS NA CULTURA DO FEIJÂO CAUPI EM POMBAL-PB
}

\author{
IDENTIFICATION OF VISITORS IN FLORAL COWPEA BEAN \\ CULTURE IN POMBAL-PB
}

\section{IDENTIFICACIÓN DE VISITANTES EN FLORAL CULTURA DE FRIJOL EN CAUPI POMBAL-PB}

\author{
José Sebastião de MELO FILHO ${ }^{1}$ \\ Mário Leno Martins VÉRAS 2 \\ Urandy Alves de MELO ${ }^{3}$ \\ Lunara de Sousa ALVES 4 \\ Fabiana Xavier COSTA 5
}

Resumo: O conhecimento da flora apícola é um passo importante para a exploração racional e programas de conservação de abelhas, facilitando as operações de manejo no apiário, como também, possibilitando a identificação, preservação e multiplicação das espécies vegetais mais importantes na área. A criação de abelhas é uma atividade que beneficia, além do apicultor, às próprias abelhas $e$ aos vegetais que dependem da sua polinização. A chave de uma apicultura produtiva é o conhecimento do comportamento dos fluxos de néctar e de pólen de uma região. Objetivou-se com este trabalho identificar visitantes florais do feijão caupi. Esta pesquisa foi realizada em condições de campo, no Centro de Ciências e Tecnologia Agroalimentar - CCTA da Universidade Federal de Campina Grande, Campus de Pombal - PB. Observou que na cultura do feijão caupi ocorreu à presença de vários visitantes florais (Apis Melíferas, Vespas Amarelas Rajadas, Abelhas Amarelas, Maribondos Pretos e Maribondos Vermelhos. A ordem mais presente foi as abelhas Apis Meliferas que representou um percentual de $34 \%$ nas flores e no momento da pesquisa observou-se Maribondos Pretos com percentual de $56 \%$ nas astes das plantas no momento das visitas observadas.

Palavras Chave: Pastagem apícola; Leguminosa; insetos.

Resumen: El conocimiento de la flora apícola es un paso importante para los programas de conservación y explotación de abejas racionales, lo que facilita las operaciones de manejo en el colmenar, sino que también permite la identificación, preservación y multiplicación de las especies vegetales más importantes de la zona. La apicultura es una actividad que beneficia además de los apicultores, las propias abejas y plantas que dependen de la polinización. La clave para una apicultura productiva es el conocimiento del comportamiento de los flujos de néctar y polen de una región. El objetivo de este trabajo fue identificar visitantes florales de caupí. Esta encuesta se realizó en condiciones de campo en el Centro de Ciencia y Tecnología Agroalimentaria - Universidad Federal CCTA de Campina Grande, en el Campus de Pombal - PB. Señaló que en la cultura caupí fue la presencia de varios visitantes florales (miel Apis, avispas amarillas Ráfagas, abejas amarillas, avispas avispas negras y Rojos. Cuanto más este orden fueron las abejas Apis que representen un porcentaje del $34 \%$ en las flores y cuando la encuesta observó avispas negras con un porcentaje del 56\% en Astes planta en el momento de las visitas observadas.

Palabras-chave: Pastos de abeja; Las legumbres; insectos.

Abstract: Knowledge of bee flora is an important step in the rational exploitation and conservation programs bees, facilitating operations management in the apiary, as well, enabling the identification, preservation and multiplication of plant species in the most important area. Keeping bees is an activity that benefits, beyond the beekeeper, and the bees themselves to plants that depend on pollination. The key to a productive beekeeping is the knowledge of the behavior of the flow of nectar and pollen of a region. The objective of this work was to identify floral visitors of cowpea. This research was conducted under field conditions, the Center for Science and Technology Agrifood - CCTA Federal University of Campina Grande, Campus de Pombal - PB. He noted that in the culture of cowpea was the presence of several floral visitors (Apis bees, wasps Gusts Yellow, Yellow Bees, wasps and wasps Black Reds. Was order more gift honey bees Apis representing a percentage of $34 \%$ on flowers and when the survey was observed wasps Black with percentage of $56 \%$ in Astes plant at the time of the visits observed.

Keywords: Grassland beekeeping; Legumes; insects

1 Mestre em Sistemas Agroindustriais, Campus Pombal UFCG. Email: sebastiaouepb@yahoo.com.br;

2 Mestrando em Agronomia, Universidade Federal da Paraíba (UFPB), Areia - PB. E-mail: mario.deus1992@bol.com.br;

3 Graduação em Licenciatura em Ciências Agrárias, Universidade Estadual da Paraíba (UEPB), Catolé do Rocha - PB. E-mail: urandyuepb@yahoo.com.br;

4 Mestranda em Sistemas Agroindustriais, Campus Pombal UFCG. Email: lunara_alvesuepb@hotmail.com;

5 Professora da Universidade Estadual da Paraíba - UEPB/Campus IV Catolé do Rocha-PB., E-mail: faby.xavierster@gmail.com; 


\section{INTRODUÇÃO}

Os primeiros insetos polinizadores eram dípteros e besouros, não muito especializados que provocavam, além da polinização, a destruição de parte das flores, hoje os principais polinizadores pertencem à três ordens: Díptera (moscas e mosquitos), Hymenoptera (vespas e abelhas), e Lepidoptera (mariposas e borboletas).A relação de mutualismo entre plantas e insetos é de grande importância para ambos e já passou por diversos tipos de alterações durante a sua evolução na busca de propiciar melhores condições aos seus participantes, já que de um lado temos as plantas buscando se reproduzir e de outro os insetos querendo se alimentar. É uma relação muito antiga que têm suas origens com os insetos filófagos, provavelmente no Carbonífero, se ampliando no Cretáceo com o aumento das angiospermas (Santos et al., 2008).

No Brasil são conhecidas mais de 400 espécies de abelhas sem ferrão que apresentam grande heterogeneidade na cor, tamanho, forma, hábitos de nidificação e população dos ninhos. Algumas se adaptam ao manejo, outras não. Embora vantajosa, a criação racional dessas abelhas é dificultada pela escassez de informações biológicas e zootécnicas, pois muitas sequer foram identificadas ao nível de espécie (Pereira, 2005).

Dentre as espécies mais conhecidas estão as abelhas mandaçaia (Melipona quadrifasciata Lep.), jataí (Tetragonisca angustula Latreielle), jandaíra (Melipona subnitida Ducke), mirim (Plebeia sp), rajada (Melipona asilvae), canudo (Scaptotrigona sp) e uruçu (Melipona scutellaris) (Lopes et al., 2005).

Além da ação humana há uma destruição, que embora reduza a população de abelhas, pode ser considerado um controle natural das populações que de um modo geral, são os ataques atacadas por aranhas, formigas, passarinhos, répteis, batráquios, vespas, traças, e até por abelhas maiores, entre muitos outros predadores (Fabichak, s/d). Por causa deste desaparecimento, em algumas regiões, como o Sudeste e Sul, poucas pessoas conhecem os sabores do mel das abelhas nativas, o que faz desse produto uma verdadeira iguaria, apresentando cores, gostos e aromas incomparáveis (Lopes, 2005), e que quando comercializado apresentam valores elevados.

Alguns estudos, bem como, práticas em campo são capazes de provar a eficiência dessas espécies como polinizadores. No México, a espécie Scaptotrigona mexicana é usada como polinizador de abacate e tem sido exportada para Israel; são utilizadas também como polinizadoras na Austrália, onde muitos criadores têm abelhas sem ferrão, cuja principal atividade é a polinização. No Brasil, os benefícios agrícolas desta atividade estão ainda em estudo, por exemplo, a Nannotrigona testaceicornis (iraí) e a Tetragonisca angustula (jataí) são utilizadas em estufas para cultivo de morango, a Melipona subnitida (jandaíra) é usada em pomares de goiaba (Psidium guajava) (Imperatiz-Fonseca et al.,2005).

As abelhas, em geral, polinizam diversas plantas cultivadas no mundo, resultando em uma estimativa de 15 a 30\% da produção mundial de alimentos (Kremen et al., 2002;Guimarães, 2006). Em especial as de vida solitária são responsáveis pela produção de bons frutos na flora nativa em agroecossistemas, que já são criadas com esta finalidade (Rego \& Albuquerque, 2006). As abelhas 
nativas são consideradas de comportamento social, mas não só estas são importantes para a polinização, as abelhas solitárias são responsáveis pela polinização de espécies vegetais como a acerola, algodão, caju, maracujá, já as abelhas africanizadas polinizam as flores do melão, pepino, eucalipto e café (Freitas et al., 2006).

Essa extinção já foi evidenciada em todos os continentes com exceção da Antártica e, embora não tenham sido avaliadas grandes extensões em todos os continentes, pode-se presumir que a degradação desses organismos seja ainda maior já que esta vem associada às ações humanas, dentre as quais destacam: a fragmentação de hábitat e outras mudanças implantadas no uso da terra, como a agricultura, e o pastoreio, a utilização de praguicidas e herbicidas, e a introdução de espécies exóticas (Buchmann \& Nabhan, 1996; Kearns et al.,1998; Cruz, 2003; Ghazoul, 2005; Santos et al., 2008).

Apesar desta importância e da fragilidade da polinização para os ecossistemas conhecidos há tanto tempo, os estudos sobre a ecologia da polinização não estão avançando adequadamente principalmente no que diz respeito aos diversos polinizadores e as plantas que são polinizadas (Eardley et al., 2006). A preservação dos organismos polinizadores é algo de extrema importância para a manutenção dos ecossistemas, bem como para preservar a diversidade genética dos vegetais. Pensando nas razões econômicas a conservação da atividade polinizadora proporciona um aumento nos ganhos principalmente quando se trata da produção de frutos e sementes (Santos et al., 2008).

Souza (2002) ressaltou que os produtos resultantes das atividades de coleta das abelhas, como mel, pólen, própolis e geléia real, representam uma alternativa econômica e ecologicamente sustentável dos recursos naturais, uma vez que a apicultura/meliponicultura tem na preservação da vegetação como primeiro requisito para sua sustentabilidade, pois sem as flores não existe a produção de mel nem de pólen. E o semi-árido, onde existem vastas extensões de terra com vegetação nativa para a produção do mel orgânico, ou seja, aquele livre de contaminação ambiental (por agrotóxicos) revela-se como uma região capaz de sobressair-se nesta atividade econômica no âmbito nacional e internacional.

A técnica da polinização é fenômeno que permite a reprodução das plantas, por transferência de pólen, alterando caracteres para aumentar a adaptação ao meio através de frutos e sementes melhores (Free, 1993). É um serviço prestado ao meio ambiente que proporciona a diversidade das espécies vegetais através de uma maior variedade genética e grande dispersão por vários habitats, é por isso um mecanismo de benefício mútuo no qual os animais buscam seu alimento e em troca auxiliam na reprodução e dispersão das plantas.

Nas últimas décadas, o desafio do setor agrícola vem sendo o desenvolvimento rural sustentável com a busca de práticas sustentáveis, que se comparem às obtidas pela agricultura tradicional, mas que impliquem em menores custos ambientais (Tilman, 1998). Esse desafio marca uma nova fase da agricultura, momento em que a sustentabilidade do modelo produtivista vem a ser questionada e que serão implantados valores ambientais nas práticas agrícolas, na opinião pública e na agenda política. Com base nesta forma de agricultura dita sustentável, muitos são os tipos de agricultura que vão surgindo dentre as quais tem-se: agricultura orgânica, biodinâmica, agricultura natural, agricultura biológica e a agricultura ecológica (Hespanhol, 2008).A utilização de abelhas é algo importante principalmente quando são empregadas as abelhas nativas, que estão em extinção 
devido à introdução da espécie exótica do gênero Apis, que apesar de produzir grande quantidade de mel estão levando a uma queda no número de indivíduos nativos do Brasil.

Diferente da agricultura convencional, também chamada de tradicional, a agroecologia tem como alicerce processos de controle de pragas e doenças que se baseiam no equilíbrio químico e fisiológico da planta, buscando maior resistência pelo equilíbrio energético e metabólico vegetal (Medeiros et al., 2007). No presente estudo objetivou-se identificar os visitantes florais das variedades do feijoeiro caupi em condições de campo, buscando identificar polinizadores efetivos em áreas agrícolas no município de Pombal - PB.

\section{LOCALIZAÇÃO}

O experimento foi conduzido no Centro de Ciências e Tecnologia Agroalimentar da Universidade Federal de Campina Grande (UFCG), campus Pombal - PB. Localizado no Sertão Paraibano, nas coordenadas geográficas $6^{\circ} 47^{\prime} 20^{\prime \prime}$ de latitude S e $37^{\circ} 48^{\prime} 01^{\prime \prime}$ de longitude W, e altitude média de $194 \mathrm{~m}$.

\section{CLIMA}

O clima da região, conforme a classificação climática de Köppen, adaptada ao Brasil (COELHO e SONCIN, 1982), do tipo BSh, que representa clima semi-árido quente e seco, com precipitação média de $750 \mathrm{~mm}^{-1}$, e evaporação média anual de $2000 \mathrm{~mm}$.

\section{MONTAGEM DO EXPERIMENTO}

O experimento foi conduzido no período de 14 a 24 de dezembro de 2012, sendo este estudo conduzido durante o florescimento do feijão caupi, os insetos visitantes florais foram coletados em 4 copos plásticos,1recipiente com tampa pra colocar os insetos,com 2 mangueiras (fina e grossa),acetona,algodão,.álcool, 1 máquina fotográfica,1 computador para tabular os dados coletados durante o momento da coleta e identificação dos insetos., em três dias consecutivos durante os horários das 6:20, 7:20, 9:00, 11:00, 13:00, 15:00 e 17:00 horas, e posteriormente foram identificados até a ordem correspondente. Foram considerados visitantes florais aqueles que coletavam néctar e/ou pólen, ou os que se alimentavam das partes florais.

Figura 1 - Materiais utilizados na coleta de visitantes florais durante o momento da pesquisa no cultivo do feijoeiro caupi, em Pombal, PB, 2013.

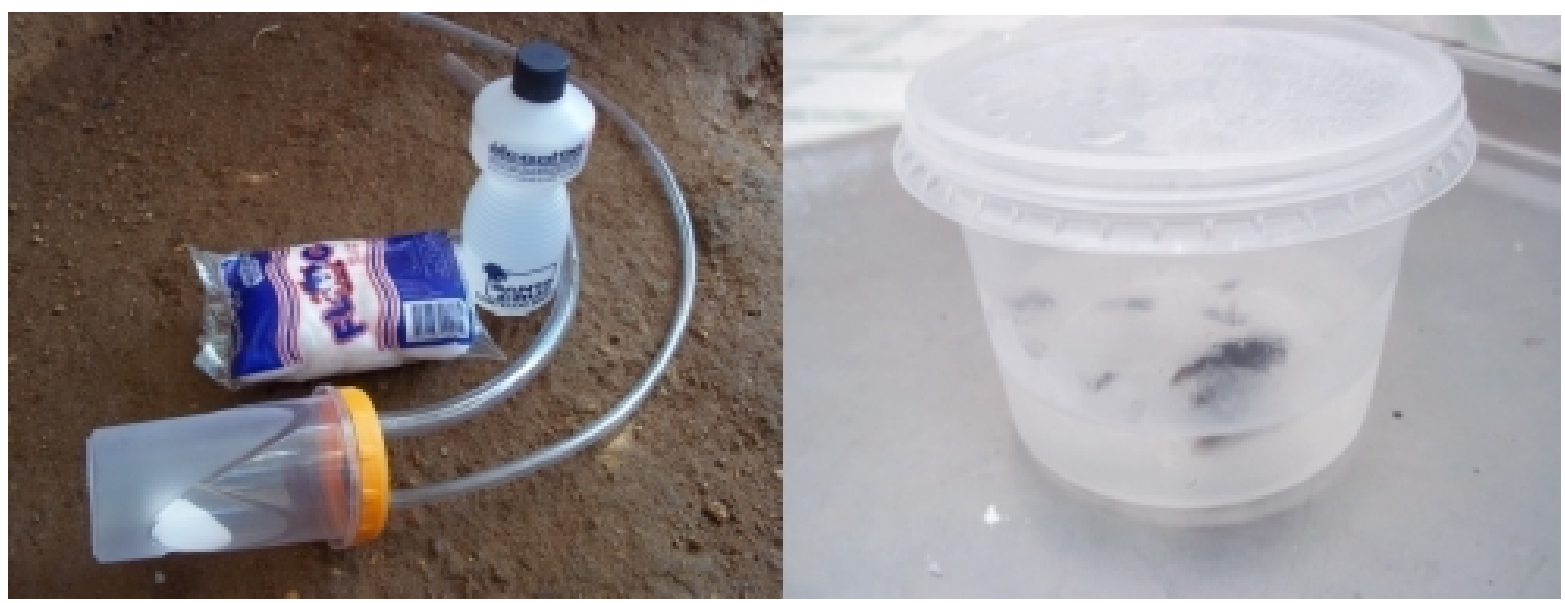




\section{RESULTADOS E DISCUSSÃO}

Na identificação e coleta dos insetos em campo, foi observado o momento que antecedeu a abertura das flores, onde constatou-se o início da abertura das flores (antese) a partir das 6:00 horas (A.M.), e concluído-se aproximadamente às 7:00 hrs (A.M.). O fechamento das flores (senescencia) iniciou-se às 11:00 hrs (A.M.), concluindo-se aproximadamente às 12:00 hrs (P.M.), nesse horário observou-se todas as flores já fechadas. Na coleta de insetos foi identificado o horário de 6:20 hrs (A.M.) com a maior incidência de insetos visitantes no cultivo do feijão caupi.Na coleta de dados observou-se insetos que almejam diversos objetivos no interior das flores que foram desde a coleta de recompensas (pólen e néctar), consumo de partes vegetais (pétalas,astes.Constatou-se 156 visitantes florais nas astes e 86 nas flores,sendo observado 242 visitantes florais em geral ,conforme a tabela 1 apresentada abaixo em ordem pelos visitantes florais que foram observadas no momento da pesquisa no cultivo do feijão caupi e suas variedades.

Tabela 1- Identificação de visitantes florais no município de Pombal - PB, 2013.

\begin{tabular}{|c|c|c|c|c|c|}
\hline Variedades & Ordem de Insetos & Astes & \multicolumn{2}{|c|}{ Flor } & \multicolumn{2}{|c|}{ Quantidade $\backslash$ visitantes } \\
\hline $\mathrm{V}_{1}$ & HP;HV;HAR;AAM;APIS & $8 ; 2 ; 3 ; 5 ; 3$ & $2 ; 3 ; 3 ; 2 ; 8$ & $56 \mathrm{HP}$ & 12 \\
\hline $\mathrm{V}_{2}$ & HP;HV;HAR;AAM;APIS & $7 ; 3 ; 4 ; 6 ; 3$ & $1 ; 2 ; 1 ; 1 ; 4$ & $28 \mathrm{HV}$ & 10 \\
\hline $\mathrm{V}_{3}$ & HP;HV;HAR;AAM;APIS & $9 ; 4 ; 3 ; 4 ; 4$ & $1 ; 1 ; 3 ; 4 ; 7$ & $21 \mathrm{HAR}$ & 16 \\
\hline $\mathrm{V}_{4}$ & HP;HV;HAR;AAM;APIS & $9 ; 6 ; 3 ; 7 ; 3$ & $3 ; 2 ; 3 ; 3 ; 5$ & $33 \mathrm{AAM}$ & 14 \\
\hline $\mathrm{V}_{5}$ & HP;HV;HAR;AAM;APIS & $12 ; 5 ; 5 ; 7 ; 3$ & $2 ; 1 ; 4 ; 2 ; 6$ & $18 \mathrm{APIS}$ & 34 \\
\hline $\mathrm{V}_{6}$ & HP;HV;HAR;AAM;APIS & $11 ; 8 ; 3 ; 4 ; 2$ & $3 ; 1 ; 2 ; 2 ; 4$ & 156 & 86 \\
\hline
\end{tabular}

De acordo com a coleta dos insetos em campo foi constatado que os visitantes florais em maior freqüência nas astes da cultura do feijão caupi, foram Maribondos Pretos com percentagem de $36 \%$ do total de visitas na espécie vegetal, e os $64 \%$ restantes correspondem a Abelhas Amarelas, Maribondos Vermelhos; Vespas Amarelas Rajadas e Apis Melíferas. De acordo com a (tabela 2), constatou-se a identificação dos visitantes florais nas astes, por ordem de insetos identificados nas variáveis observadas no cultivo do feijoeiro caupi. De acordo com Simpson \& Neff (1983) indicaram que partes florais, em diversas espécies, ao longo do tempo, têm se tomado em tecidos nutritivos para insetos visitantes. Tais tecidos são de origem epidérmica e parenquimática, contendo açúcares, amido, proteínas e lipídios.

A maioria dos grupos de insetos visitantes florais, especialmente Coleoptera, Hymenoptera, Lepidoptera e Diptera, utilizam pólen (fonte protéica) e néctar (fonte energética) para o vôo dos adultos e/ou também para a maturação dos ovos. As abelhas, porém, são totalmente dependentes dos recursos florais durante o estágio larval e adulto. O alto grau de dependência das abelhas pelos recursos florais reflete-se nas inúmeras adaptações morfológicas para coleta e transporte desses recursos (MICHENER, 1974; ROUBIK, 1989; RAMALHO et al., 1991; NEFF \& SIMPSON, 1993).

Abelhas solitárias e vespas foram visualizadas coletando néctar e pólen das partes florais 
do feijão caupi durante o período em que a mesma manteve-se aberta, após o início da senescencia, foram observados espécimes representantes dos indivíduos observados anteriormente utilizando o receptáculo floral como ambiente de descanso, para adentrar nas flores utilizavam seus primeiros pares de patas com o fim de abrir as pétalas e introduzirem-se no interior das flores.

Tabela 2 - Percentagem nas astes de identificação dos visitantes florais na cultura do feijão caupi, no município de Pombal - PB, 2013.

\begin{tabular}{|c|c|c|}
\hline Ordem de visitantes & Astes & $\mathbf{( \% )}$ \\
\hline HP & 56 & 36 \\
\hline AAM & 33 & 21 \\
\hline HV & 28 & 18 \\
\hline HAR & 21 & 13 \\
\hline APIS & 18 & 12 \\
\hline TOTAL & 156 & 100 \\
\hline
\end{tabular}

Durante a observação de visitantes na flor do feijão caupi em estudo, foram observadas as seguintes ordens de insetos na coleta de pólen e/ou néctar: Apis Melíferas; Vespas Amarelas Rajadas; Abelhas Amarelas; Maribondo Preto e Maribondo Vermelho. O fato de ser encontrada enorme variedade de visitantes florais, além da coleta de alimento sejam potenciais polinizadores, corrobora com muitas espécies vegetais nas regiões tropicais e temperadas que podem apresentar mais de uma síndrome de polinização, e a interação planta-polinizadora é uma relação flexível (PROCTOR et al. 1996) As abelhas Apis Melíferas foram observadas várias vezes visitando flores do feijoeiro cauoi, com percentual de $39,5 \%$ do total de visitas nesta espécie vegetal, os $60,5 \%$ restantes correspondem a Vespas Amarelas Rajadas; Abelhas Amarelas; Maribondos Pretos e Maribondos Vermelhos. A baixa freqüência das demais espécies pode estar relacionada com as grandes populações das colônias de Apis Melíferas, quando comparadas a outras espécies de abelhas e demais insetos.

De acordo com Piedade (1998), em Merremia aegyptia observou-se que o néctar foi forrageado por A. mellifera, enquanto o pólen foi coletado por Trigona spinipes. Esta diferença de comportamento entre as abelhas é atribuída às características morfológicas florais, que selecionam as abelhas com comprimento de língua adequado para ter acesso ao néctar. No caso de T. spinipes, estas apresentam comprimento de probóscide inferior ao comprimento do tubo da corola de M. aegyptia, impedindo que esta abelha tenha acesso ao néctar, justificando o comportamento de coleta exclusiva de pólen nas flores desta invasora.

Piedade (1998), reforça que a polinização por abelhas generalistas, como A. mellifera e T. spinipes, associada a possibilidade de autofecundarão e polinização cruzada, confere a esta Convolvulaceae adaptação adequada a plantas daninhas e invasoras de culturas. Assim, J. Multiflora apresenta características que permitem classificá-la como uma "planta invasora ideal" (BAKER 1974), pois além da autocompatibilidade, apresentam altas taxas de frutificação e produção de sementes/fruto, bem como altas taxas de germinação.

Para Free (1993) e Freitas (1995), diferente de outros polinizadores, as abelhas são extremamente eficientes na polinização tanto de plantas cultivadas quanto silvestres porque possuem os recursos florais (pólen, néctar e óleos) como suas únicas fontes de alimento ou produtos e serviços 
necessários à sua sobrevivência como no caso das essências florais (usadas por machos de algumas espécies para produzirem seus feromônios sexuais e atraírem fêmeas para o acasalamento), abrigos de inimigos e intempéries, resinas vegetais, locais de acasalamento e de encontrar parceiros sexuais, fonte de calor (machos de algumas espécies aquecem-se em flores nas noites frias) dormem nas noites frias, etc. Isto obriga as abelhas a estarem em contato constante com as flores, aumentando enormemente a chance de transferirem grãos de pólen dentro da mesma flor ou entre flores diferentes da mesma espécie de planta. As visitas às flores feitas por outros animais são eventuais e a grande maioria não possui as flores como sua única fonte alimentar e/ou a visitam somente em momentos isolados.

É importante salientar que durante a coleta de néctar às 15:00 horas as flores encontravam-se fechadas, apesar disso algumas abelhas africanizadas utilizavam o primeiro par de patas para afastar as pétalas e adentrar nas flores, a partir dessa visualização tornou-se viável a coleta de néctar no horário referido. Este fato é confirmado por Winston (2003), o mesmo afirma que para flores fechadas, as abelhas forçam com suas pernas dianteiras a separação das pétalas, e então, junta o pólen com as partes bucais e as pernas dianteiras, o mesmo autor ainda informa que para flores tubulares as operárias inserem a proboscíde na corola a procura de néctar, e o pólen é coletado casualmente quando adere às partes bucais ou às pernas dianteiras, fato também constatado neste estudo com Merremia aegyptia. Durante esta coleta de pólen involuntária, pode ocorrer a autopolinização, e ainda mais freqüente, já que as abelhas visitam grande número de flores, a polinização cruzada. Durante a coleta, a abelha africanizada e algumas vespas, contatam as estruturas reprodutivas com a parte ventral do corpo, onde o pólen é depositado, caracterizando a polinização esternotribica. A espécie Merremia aegyptia pode ser classificada como melitófila (FAEGRI \& VAN DER PIJL 1980).

Tabela 3 - Percentagem nas flores de identificação dos visitantes florais na cultura do feijão caupi, no município de Pombal - PB, 2013.

\begin{tabular}{|c|c|c|}
\hline Ordem de visitantes & Flor & $\mathbf{( \% )}$ \\
\hline APIS & 34 & 39,5 \\
\hline HAR & 16 & 18,6 \\
\hline AAM & 14 & 16 \\
\hline HP & 12 & 13,9 \\
\hline HV & 10 & 12 \\
\hline TOTAL & 86 & 100 \\
\hline
\end{tabular}

\section{CONSIDERAÇÕES FINAIS}

1. Observou-se que a Apis Melífera apresentou hábito diurno, a antese iniciou-se às 6:00, e concluiu-se aproximadamente às 12:00 horas;

2. A coleta dos visitantes florais no feijão caupi foi às 6:20 horas, a ordem mais presente na flor foram as abelhas, Apis Melíferas representando uma porcentagem de 39,5\% das visitas observadas, e os 60,5 \% restante refere-se a Vespas Amarelas Rajadas, Abelhas Amarelas,Maribondos Pretos e Maribondos Vermelhos.

3. Do total de insetos visitantes florais na aste coletados o maior percentual é de Maribondos Pretos com percentual de $36 \%$ e os demais foram constatado uma percentagem de $64 \%$ durante a coleta dos intsetos. 


\section{REFERÊNCIAS BIBLIOGRÁFICAS}

ALBUQUERQUE, L.B., VELÁZQUEZ, A. \& VASCONCELLOS-NETO, J. Composição florística de solanaceae e suas síndromes de polinização e dispersão de sementes em florestas mesófilas neotropicais. Interciencia. v. 31, n. 011, p. 807-816, 2006.

BAKER, H.G.. The evolution of weeds. Annual Review of Ecology and Systematics 5:124.1974.

CRUZ, D.O. Uso e eficiência da abelha jandaíra (Melipona subnitida Ducke) na polinização do pimentão (Capsicum annuum L.) sob cultivo protegido. Fortaleza, CE: Universidade Federal do Ceará (UFC), 2003. 71p. Dissertação Mestrado.

Dissertação Mestrado.BUCHMANN, S.L. \& Nabhan, G.P. The Forgotten Pollinators.

Washington, DC: Island. 1996. 292 p.

EARDLEY, C., ROHT, D., ClARKE, L, BUCHMANN, S. \& GEMMILl, B. Pollinators and pollination:A resource book for policy and practice. Pretoria, South Africa: African Pollinator Iniciative (API). 2006. 96p.

FABICHAK, I. Abelhas indígenas sem ferrão Jataí. São Paulo: Nobel, s/d. 53 p.

FAEGRI, K. \& VAN DER PIJL, L.. The principles of pollination ecology. Pergamon Press, Oxford. 1980.

FREE, J.B. Insect pollination of crops. Lodon: Academic Press. 1993. 684p.

FREITAS, B.M. The pollination efficiency of foraging bees on apple (Malus domestica Borkh) and cashew (Anacardium occidentale L.). University of Wales, Cardiff, Grã-Bretanha, 1995. 197p. Tese Doutorado.

GHAZOUL, J. (2005) Buzziness as usual? Questioning the global pollination crisis. Trends Ecol. Evol. v. 20, n.7. p. 367-373.

GUIMARÃES, R.A. Abelhas (Hemynoptera: Apoidea) visitantes das flores de goiaba (Psidium guajava L.), laranja (Citrus sinensis L.) e tangerina (Citrus reticulata B.) em pomares comerciais em Salinas - MG. Vitória da Conquista, BA: Universidade Estadual do Sudoeste da Bahia, 2006. 85p. Dissertação Mestrado.

HESPANHOL, R.A.M. Perspectivas da agricultura sustentável no Brasil. Confins. n.2. 2008. http://confins.revues.org/document2353.html. 01 setembro 2008.

IMPERATRIZ-FONSECA, V.L.; Gonçalves, L.S.; Jong, D.; Freitas, B.M.; Castro, M.S.; Santos,I.A.; Venturieri, G.C. Abelhas e Desenvolvimento Rural no Brasil. Mensagem Doce, n 80, 2005.

KEARNS, C.A., INOUYE, D.W. \& WASER, N. Endangered mutualisms: The Conservation of

KREMEN, C., WILLIAMS, N.M. \& THORP, R.W. Crop pollination from native bees at risk from agricultural intensification. Proceedings of the National Academy of Science of the United States of America. Stanford, v. 99, n. 26, p. 16812-16816, 2002.

LOPES, M.; FERREIRA, J.B.; SANTOS, G. dos. Abelhas sem-ferrão: a biodiversidade invisível. Agriculturas, v. 2, n. 4, 2005.

MEDEIROS, M.B.; SANTOS, D.; BARBOSA, A.S. Produtos trofobióticos para proteção de plantas. Rev. Bras. de Agroecologia, v. 2, n. 2, p. 1268-1272, 2007.

MICHENER, C.D. The social behavior of bees: a comparative study. Cambridge: The Blacknap Press, 1974. 404 p.

PEREIRA, F.M. Abelhas sem ferrão a importância da preservação. 2005. http://www.embrapa.br/noticias/artigos/folder. 2005-02-02.1550581232/artigo. 2005-1229.3499364899/mostra_artigo. 20 outubro 2006.

PIEDADE, L.H.. Biologia da polinização e reprodutiva de sete espécies de Convolvulaceae na caatinga do Sertão de Pernambuco. Tese de doutorado, Universidade Estadual de Campinas. 1998. Plant-Pollinators Interactions. Annual Review of Ecology and Systematics. v. 29, p. 83-112, 1998.

PROCTOR, M., P. YEO \& A. L. LACK.. The natural history of pollination. London, Harper Collins Publishers, 463 p. 1996.

RAMALHO, M., Imperatriz-Fonseca, V.L. \& Kleinert-Giovannini, A. Ecologia nutricional de insetos sociais. In: Panizzi, A.R. \& Parra, R.P. Ecologia nutricional de insetos e suas Implicações no manejo de pragas. São Paulo, Editora Manole Ltda, p 225-252. 1991.

RIBEIRO, M.F. \& GAGLIANONE, M.C. Bumble bees and Solitary bees. In: Imperatriz-Fonseca, V.L., 
Saraiva, A.M. \& De Jong, D. Bees as pollinators in Brazil: assessing the status and suggesting best practices. Ribeirão Preto: Holos, 2006, p 55-62.

ROUBIK, D.W. Ecology and natural history of tropical bees. Cambridge: University Press, $1989.514 \mathrm{p}$.

SANTOS, A.B., NASCIMENTO, F.S. \& SOUZA, C.S. Polinização, um importante serviço prestado ao meio ambiente. In: Seabra, G.F. (Org.) A Conferência da Terra: Fórum Internacional do Meio Ambiente. Questões globais e soluções locais. João Pessoa-PB: Editora Universitária da UFPB, 2008. p. 640-646.

SIMPSON, B.B., NEFF, J.L. Evolution and diversity of floral rewards.ln: JONES, C.E., LITTER,R.J. Handbook of experimental pollination biology. New York: Soco Acad. Ed., 1983. p. 142-159.

SOUSA, D.C.. Apicultura Organica: Alternativa para Exploração da Região do Semi Árido Nordestino. In: Congresso Brasileiro de Apicultura, Anais..., Campo Grande, 14:133-135.2002.

TILMAN, D. The greening of green re revolution. Nature. n. 396, p. 211-212, 1998.

WINSTON, Mark L. A biologia da Abelha. Tradução de Carlos A. Osowski - Porto Alegre:Magister, 2003.276p. 